In Situ

Au regard des

sciences sociales
In Situ. Au regard des sciences sociales

$2 \mid 2021$

Patrimoine et commun(s)

\title{
Le Patrimoine saisi par les associations, vingt ans après
}

Entretien avec Guy Saez et Hervé Glevarec à propos d'une enquête pionnière sur l'engouement patrimonial en France

Claire Bullen, Cyril Isnart, Hervé Glevarec et Guy Saez

\section{OpenEdition}

\section{Journals}

Édition électronique

URL : https://journals.openedition.org/insituarss/1434

DOI : $10.4000 /$ insituarss. 1434

ISSN : 2680-4972

Éditeur

Ministère de la Culture

Référence électronique

Claire Bullen, Cyril Isnart, Hervé Glevarec et Guy Saez, «Le Patrimoine saisi par les associations, vingt ans après », In Situ. Au regard des sciences sociales [En ligne], 2 | 2021, mis en ligne le 18 mars 2021, consulté le 23 janvier 2023. URL : http://journals.openedition.org/insituarss/1434 ; DOI : https:// doi.org/10.4000/insituarss. 1434

Ce document a été généré automatiquement le 23 janvier 2023.

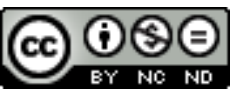

Creative Commons - Attribution - Pas d'Utilisation Commerciale - Pas de Modification 4.0 International - CC BY-NC-ND 4.0

https://creativecommons.org/licenses/by-nc-nd/4.0/ 


\section{Le Patrimoine saisi par les associations, vingt ans après}

Entretien avec Guy Saez et Hervé Glevarec à propos d'une enquête pionnière sur l'engouement patrimonial en France

Claire Bullen, Cyril Isnart, Hervé Glevarec et Guy Saez

1 Le Patrimoine saisi par les associations (Glevarec \& Saez 2002) a été publié il y a presque vingt ans et une version électronique vient tout juste de paraître. Cet ouvrage est devenu, au fil des années, l'une des références incontournables des études de sciences sociales traitant du rapport de la société française au patrimoine culturel. Les auteurs de cette publication, Guy Saez, chercheur au CNRS et spécialiste des politiques culturelles en France, ayant l'habitude de travailler pour le ministère de la Culture, et Hervé Glevarec, alors jeune docteur en sociologie de la culture et recruté par la suite également au CNRS, ont formé un tandem complémentaire qui a mis en lumière de manière systématique et fine la vitalité, les valeurs et les pratiques des associations patrimoniales de la France de la fin du Xx siècle.

2 Il ne s'agissait pas d'explorer les grandes fédérations de bénévoles, telle Rempart, les institutions nationales établies, comme Vieilles Maisons françaises, ou les anciennes et nobles sociétés savantes. L'accent a été mis sur les "petites » associations s'occupant du patrimoine local, dont le rayonnement ne dépassait pas l'échelle départementale et dont l'intérêt se portait vers cette France rurale, artisanale, ouvrière, qui semblait vouée à disparaître du paysage mémoriel à l'orée du Xxi ${ }^{\mathrm{e}}$ siècle. Le fait que l'enquête qui a donné lieu à la publication du livre provient d'une commande directe du ministère de la Culture signe l'attention portée par les pouvoirs publics aux évolutions les plus récentes de la société française, en diversifiant les données et les analyses qui se concentraient alors sur les études périodiques des pratiques culturelles des Français.

3 L'enquête sur les associations de patrimoine en France révélait, sans doute pour la première fois de manière aussi systématique, statistique, ethnographique et comparée, que les lieux et les dispositifs du patrimoine en France avaient changé et que la sociologie et l'histoire que l'on pouvait en faire ne seraient plus jamais les mêmes. Elle 
entrait en effet en écho avec deux mouvements profonds des sociétés européennes dans leur ensemble ${ }^{1}$.

D'abord la France, comme d'autres États membres de l'Union Européenne, avait mis en place un plan de décentralisation, voulu par le pouvoir central, qui accompagnait une prise de conscience et une volonté d'autonomie des pouvoirs régionaux pour la gestion de leurs espaces, de leurs ressources et de leurs populations. Cet essor des régions contribuait à la montée en puissance, parfois gênante pour un État centralisé et égalitaire comme la France, des particularismes de territoires ou de groupes dont le destin et le passé semblaient se différencier du grand récit national. Les conflits mémoriels ou de reconnaissance prenaient le dessus sur l'histoire nationale unifiée, redistribuant ainsi l'attention et le souci vers des passés pluriels et vers différentes couches de la société.

5 Ensuite, les qualifications patrimoniales touchaient de nouvelles catégories de productions humaines et ne se cantonnaient plus à l'architecture, aux archives notariées, aux objets d'art ou aux ruines antiques. Le patrimoine culturel maillait dès lors l'espace de plus en plus densément, en ne se limitant plus aux quelques grands lieux de mémoire du pays. Les savoir-faire techniques, les objets domestiques, les lieux de sociabilité coutumiers, les productions agricoles de microrégions entraient, par l'entremise de nouveaux acteurs, notamment associatifs, dans le champ patrimonial en bousculant quelque peu les procédures administratives de l'Inventaire.

6 À ces deux transformations marquantes des sociétés européennes, répondait un renouvellement des objets de recherche des sciences humaines et sociales qui ont alors pris en compte cette dynamique patrimoniale inédite. L'étude d'Hervé Glevarec et de Guy Saez a ainsi marqué le début d'une lignée de travaux universitaires sur les usages locaux et les appropriations civiles du patrimoine culturel dont les sociologues (Rautenberg 2003; Micoud 2005 ; Jeudy 2001 ; Davalon 2006), les géographes (Di Méo 2007; Gravari-Barbas \& Guichard-Anguis 2003), des historiens du contemporain (Bonniol \& Crivello 2004, Hartog 2003) et les ethnologues (Fabre 2000 ; Fabre \& Iuso 2009 ; Tornatore 2004 ; Sagnes 2000) ont fait un champ à part entière de leur discipline, tout en se démarquant d'une histoire du patrimoine principalement tournée vers les institutions paradigmatiques du musée et du monument national (Choay 1992 ; Poulot 2006 ; Pomian 2003 ; Leniaud 2002). Dans la même temporalité, le monde académique anglo-saxon s'est lui aussi penché sur ces appétits patrimoniaux populaires. Anthropologues, folkloristes, historiens ont su repérer en Angleterre, aux États-Unis, en Europe du Sud ou de l'Est, des tendances équivalentes à l'expansion du domaine et des acteurs patrimoniaux en France. Le goût du passé et la nostalgie, parfois remis en cause par les maittres d'une histoire critique (Lowenthal 1985), sont devenus des objets banals des études contemporaines, au point que les petits musées ruraux (Macdonald 2002), le folklore (Bendix 2002) ou le passé ouvrier (Smith, Shackel \& Campbell 2011) apparaissent aujourd'hui comme des lieux communs des études culturelles européennes. 
Figure 1

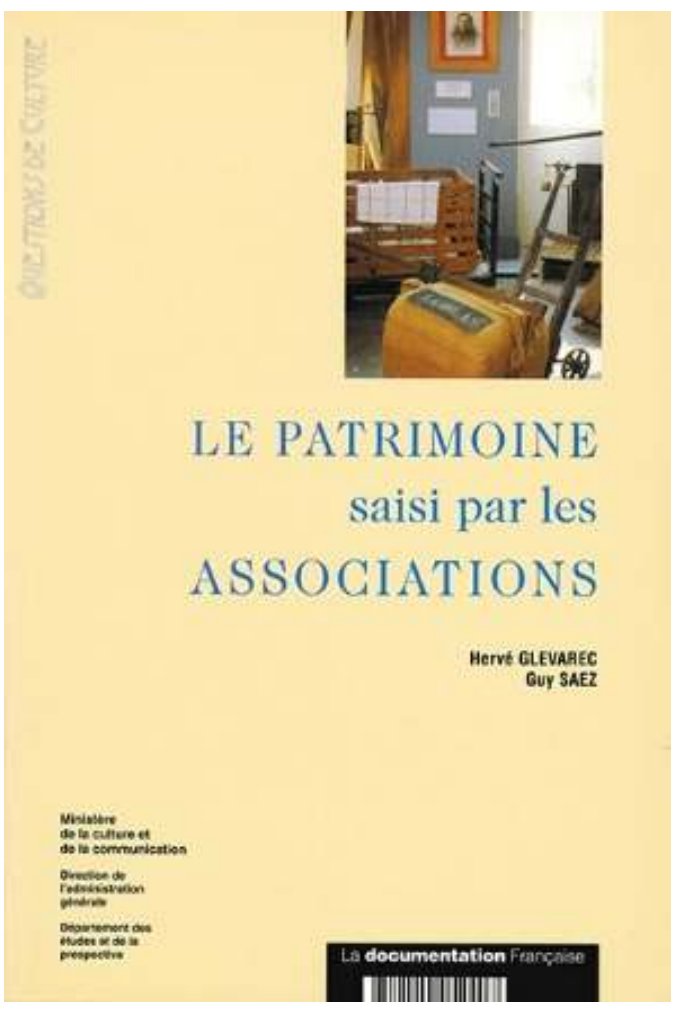

Couverture de la première édition du Patrimoine saisi par les associations illustrée d'une vue d'un musée local : un exemple de mise en scène d'objets par les associations.

(c) La Documentation française.

7 Le livre de Glévarec et Saez témoigne donc d'un moment historique singulier l'ouverture du champ patrimonial - et d'une sociologie particulière - le monde associatif, localisé et de classe moyenne. On mesure aujourd'hui l'influence et les effets de cette histoire et de cette sociologie sur l'image patrimoniale des territoires que différents acteurs culturels ont façonné depuis les années 1980.

8 L'entretien réalisé une vingtaine d'année après la publication du livre décrit les présupposés de l'enquête, ses découvertes, ses choix méthodologiques et les lignes d'interprétation qui ont conduit à l'établissement du triple diagnostique dont le livre rend compte : l'élargissement des catégories des objets et acteurs patrimoniaux, le rôle des valeurs morales dans les pratiques patrimoniales ordinaires, et la centralité de l'échelle locale dans le souci du passé. Ces trois thématiques se retrouvent encore aisément dans la littérature contemporaine et il n'est pas difficile de ranger Le Patrimoine saisi par les associations parmi les ouvrages classiques et fondateurs pour qui souhaite comprendre la place du patrimoine dans les sociétés européennes.

Depuis la publication de cette enquête - les auteurs en témoignent rétrospectivement dans l'entretien -, le domaine de l'action culturelle, et celui du patrimoine culturel en particulier, a connu de nouvelles évolutions, affichées parfois comme de véritables changements de paradigmes politiques et intellectuels, voire moraux. La lecture du livre et de l'entretien nous permettent d'en prendre la mesure. On ne pourra toutes les citer sans répéter inutilement les propos des auteurs, mais rappelons simplement: les principes de participation et de sélection citoyenne du patrimoine tels qu'ils sont formulés par la Convention sur la sauvegarde du patrimoine culturel immatériel de 
l'Unesco (2003) ou par la Convention-cadre du Conseil de l'Europe sur la valeur du patrimoine culturel pour la société (2005); l'internationalisation de plus en plus prégnante des enjeux de la qualification patrimoniale via l'Unesco et le tourisme; la place grandissante des espaces urbains dans les politiques culturelles via les programmes régionaux européens; ou encore l'individualisation du rapport au patrimoine grâce aux techniques et aux outils numériques qui n'existaient pas lors de l'enquête de Glevarec et Saez au tournant du siècle dernier.

L'entretien qui suit ne se présente donc pas simplement comme une archive d'histoire des sciences sociales ou une introduction à une contribution majeure des sciences sociales du patrimoine. Il montre également la valeur historique des recherches ethnographiques et sociologiques, au moment où il devient possible, grâce à l'accumulation et la comparaison des études entreprises depuis plus de vingt ans, de mesurer les transformations d'un champ social tel que le patrimoine culturel. Alors qu'il condense aujourd'hui des enjeux économiques, identitaires, politiques et symboliques centraux, le patrimoine culturel, en tant qu'objet des sciences sociales, offre également des opportunités scientifiques et intellectuelles riches et passionnantes pour les futures générations de chercheurs.

Claire Bullen et Cyril Isnart ont réalisé l'entretien au domicile de Guy Saez à Grenoble, avec Hervé Glevarec en visioconférence, en avril 2018, après un déjeuner composé de mets régionaux - signe de la curiosité toujours intacte de leur hôte pour les cultures locales.

\section{Une enquête en contexte}

Cyril Isnart [CI] - Pour commencer, vous pourriez rappeler quelle a été votre formation universitaire et où vous vous situiez à l'époque de la publication du livre. Était-ce un travail qui s'insérait dans vos thématiques de recherche à ce moment de votre carrière?

Hervé Glevarec [HG] - J'étais à l'époque tout jeune chercheur, frais émoulu de ma thèse de doctorat en sociologie. Cette enquête m'a procuré un cadre exceptionnel, avec Guy Saez qui m'a pris sous son épaule - il est mon âné et spécialiste des politiques publiques. Je venais de sortir de ma thèse sur la radio France Culture menée dans une perspective de sociologie des professionnels et d'ethnographie du travail de studio, sous la direction de Pierre-Michel Menger à l'EHESS, après avoir suivi un cursus de sociologie universitaire classique à Amiens et à Grenoble. Je n'avais pas fréquenté Guy Saez, mais le fait d'être grenoblois a dû contribuer à notre bonne entente. J'ai mené cette enquête en tant que chargé d'étude contractuel au CNRS, lui-même rétribué par le ministère de la Culture, avant que d'être recruté comme chargé de recherche au CNRS et d'y travailler jusqu'à maintenant.

Notre association - mais Guy en sait peut-être davantage -, a été le fait du ministère de la Culture, notamment de Dominique Jamet ${ }^{2}$ qui nous a mis en relation car elle souhaitait une relation entre un jeune chercheur et un aîné, avec un souci assez précis de mesurer le champ associatif patrimonial. Ils voulaient des chiffres, savoir combien il y avait de créations d'association, avec l'exigence d'un état des lieux. Et puis ils voulaient une enquête de terrain, qui a été particulièrement intéressante.

Guy Saez [GS] - Pour ma part, j'étais directeur de l'unité mixte de recherche Cerat à l'Institut d'études politiques de Grenoble et je dirigeais des travaux sur les politiques culturelles, financés pour la plupart par le département d'Étude et de Prospective du 
ministère de la Culture (DEPS). Cette enquête paraissait nécessaire au ministère car il souhaitait mieux prendre en compte, après la parution de l'Enquête sur les pratiques culturelles des Français en 1997, les amateurs comme une composante un peu oubliée des politiques culturelles. C'est ainsi que cette enquête nous a été confiée. Remarquons qu'elle intervient dans ce moment particulier de réflexion sur les politiques culturelles où l'on "découvre» les amateurs, alors que la plupart des travaux portaient sur l'offre et les professionnels. En ce sens, les amateurs c'est le remords du sociologue, parce qu'il ne les voit pas, non pas qu'il soit aveugle, mais parce qu'il travaille avec les moyens qu'on lui donne et, en général, on lui donne les moyens d'étudier le public et pas les amateurs.

Cl-Est-ce que l'apparition de cet objet d'étude, les amateurs du patrimoine, les associations patrimoniales, a eu une influence sur votre réflexion sur la sociologie des politiques publiques culturelles?

GS - J'avais travaillé sur les associations culturelles, dans la mesure où en France le champ des politiques culturelles est historiquement et structurellement lié aux associations. Juridiquement aussi, puisqu'un grand nombre d'institutions culturelles ont des formes associatives. On peut dire sans se tromper que les projets artistiques et culturels naissent souvent des associations et qu'il y a ensuite un processus d'institutionnalisation. Et si les associations disparaissent, évoluent, se transforment par la suite, elles restent un élément structurant des politiques culturelles. Par ailleurs, j'avais fait un travail monographique sur les associations nées à Grenoble entre 1944 et 1988, et j'avais été frappé par l'extraordinaire croissance des années 1970 et 1980, une croissance qui constitue une énigme sociologique passionnante.

Claire Bullen $[C B]$ - Est-ce que les associations patrimoniales ont suivi la même évolution?

GS - L'évolution du nombre des associations patrimoniales était en phase avec ce mouvement de croissance des associations. Mais on peut dire qu'il y a à cette époque un tournant culturel des associations. Auparavant, le contingent associatif le plus fourni relevait du domaine sportif, alors qu'au tournant des années 1980 ce sont des associations culturelles qui dominent.

$H G$ - J'ajouterai que, du point de vue de la demande institutionnelle, ce travail sur les associations demeure un peu extravagant, parce que je n'ai pas l'impression que depuis lors il y ait eu une demande aussi forte d'expertise et d'actualisation des données sur ce thème. L'un de nos résultats est le constat d'un éloignement entre l'appropriation patrimoniale associative et l'État centralisé, les Drac et l'Inventaire. Mais même si le ministère nous a laissé toute liberté pour réaliser cette enquête, il y avait un questionnement sur ces associations qui émergeaient, qui commençaient à revendiquer, peut-être à contester. Sans doute voulait-il connaître un petit peu mieux ce monde associatif et le cadrer. Je me souviens également que nous étions à une période où, en dehors de l'enquête sur les pratiques culturelles des Français, il y avait encore très peu d'information et d'études sur le champ associatif patrimonial en France. Quand il a fallu recenser les associations, on a dû envoyer des centaines de lettres aux communes, un travail de bénédictin, et du côté des pratiques amateurs spécifiquement tournées vers le patrimonial, nous n'avions que des données très agrégées. On manquait donc d'information sur deux plans : les données quantitatives sur le champ associatif, et les pratiques patrimoniales amateurs du côté des individus eux-mêmes. 
GS - Je confirme ce que dit Hervé sur les deux plans. D'une part - et c'est intéressant de le signaler car cela donne une idée de la manière dont la recherche se fabrique dans l'administration française -, la demande vient d'abord de la direction du Patrimoine et de l'Architecture. Ce n'est pas le DEPS seul qui s'est intéressé à la question. C'est une interrogation de l'administration centrale, inquiète de voir affluer des demandes nombreuses qu'elles ne connaît pas et qu'elle ne contrôle pas, avec toutes sortes de médiateurs, des élus, des architectes... De leur côté, les acteurs institutionnels disent au ministère : on ne sait pas très bien ce qu'il se passe, c'est un peu gênant pour faire notre travail parce qu'il y a une multitude de demandes dans tous les sens. À partir de cette inquiétude initiale, le DEPS, qui est le médiateur entre le ministère et les chercheurs, a reformulé la question et nous a laissé une entière liberté de travail. D'autre part, il est clair qu'il n'y avait pas d'appareil statistique correct. Il n'y en a toujours pas. La réalité de la vie associative demeure assez peu travaillée, les sociologues se sont peu emparés du champ, et on en reste à une connaissance loin d'être optimale, aussi bien du point de vue statistique que de la sociabilité et du rapport à l'État. J'ajoute que l'intérêt se concentre maintenant sur le champ associatif de l'économie sociale et solidaire, qui est une priorité du gouvernement.

Figure 2

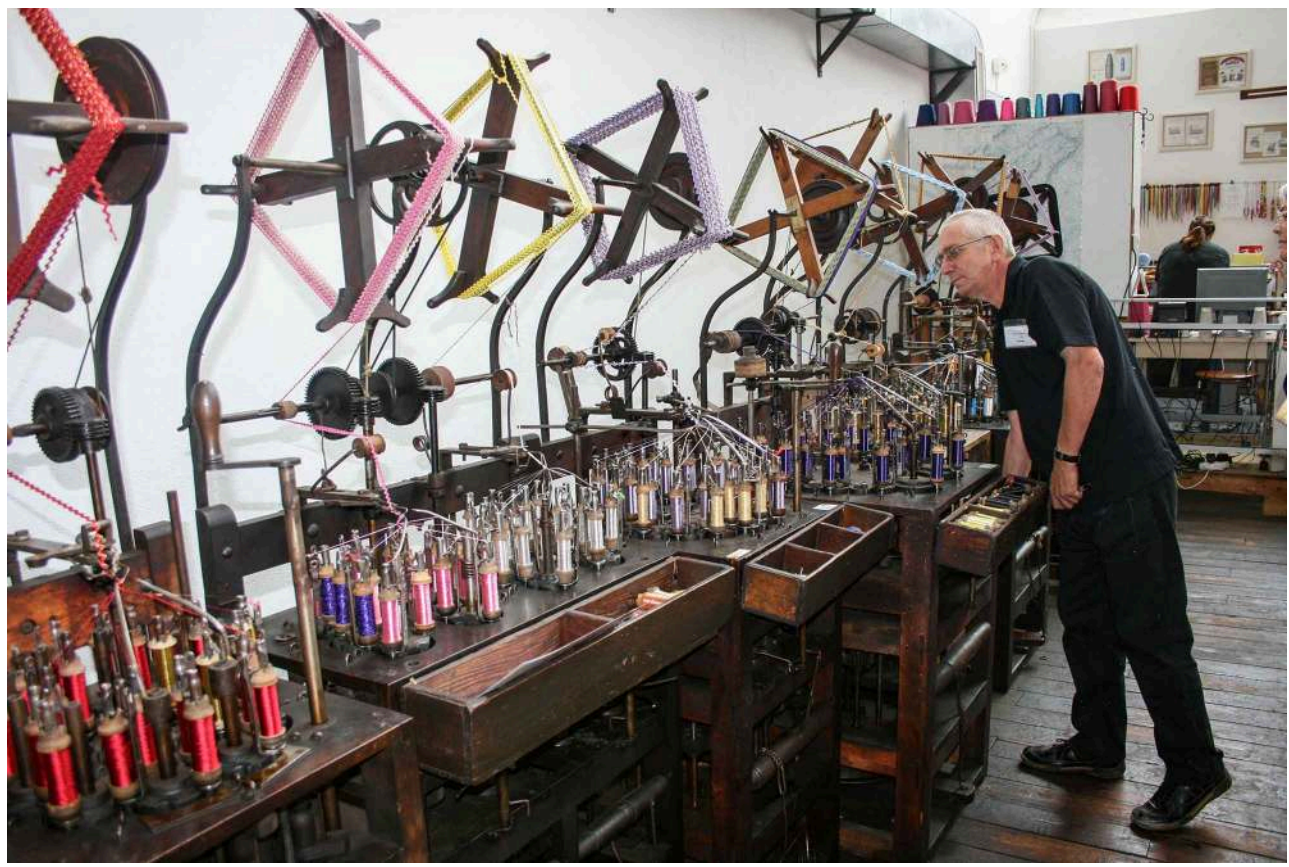

D'autres patrimoines sont portés par des amateurs, qui interrogent l'administration du patrimoine culturel. Maison des tresses et lacets installée au Moulin-Pinte, en vallée du Dorlay (Loire), 2010.

(c) Taguelmoust, distr. Creative Commons (sous licence CC BY 3.0).

$\mathrm{Cl}$ - Une question sur cette volonté de contrôle du ministère sur les associations. En ethnologie, on connaît le «rapport Benzaïd» de 1977, qui propose un contrôle et un encadrement de l'ethnologie sauvage et amateur en France. Votre enquête arrive vingt ans après. Est-ce que le rapport est précurseur - est-ce le premier signal de cet 
ensauvagement de la culture -, ou y avait-il d'autres études ou rapports qui pointaient cette évolution?

GS - Ce rapport est un peu contre-intuitif car l'ethnologie française doit beaucoup à des gens comme Paul Rivet, Georges-Henri Rivière, Paul-Henri Chombart de Lauwe qui ont mis en valeur l'ethnologie amateur, à travers des enquêtes " participatives » de certains milieux sociaux. Au moment où le rapport Benzaïd est paru, il y avait une volonté d'institutionnaliser la profession d'ethnologue et la place de l'ethnologie au ministère. Par ailleurs, au début des années 1970, l'influenwce de l'historien Michel de Certeau (1980) a été considérable pour la réévaluation de la «culture au quotidien ». Mais elle est restée une influence intellectuelle qui ne s'est pas transférée dans l'action politico-administrative.

HG - En tant que jeune chercheur, je suis arrivé dans une posture assez ouverte sur le terrain. Pour ce qui concerne le contexte intellectuel, il est vrai que la rencontre avec Guy qui est un chercheur très ouvert, et moi qui ne suis pas, par formation, un bourdieusien très critique - je pouvais l'être un peu tout de même... Et la théorie critique peut être appliquée aux associations. Je me souviens d'avoir lu à l'époque des papiers très critiques sur l'appropriation passéiste ou l'invention du passé par les associations et les amateurs, et aussi sur le fait est que notre livre a développé une approche compréhensive de ces pratiques. On a essayé de restituer les significations de cette appropriation patrimoniale qui peut, bien entendu souffrir, de passéisme, ou démontrer un rapport un peu tordu aux savoirs. Mais avoir restitué, sans a priori critique et de manière posée, est une des meilleures leçons que j'ai apprises de ce terrain. Et depuis, je vois le patrimoine et le monde associatif d'un œil beaucoup plus nuancé et compréhensif. Une sociologie critique qui regarderait les choses d'en haut n'est pas très productive. Et pour aller plus loin : est-ce que cet ouvrage a fait école? Je ne sais pas... Mais en lisant le dernier ouvrage de Luc Boltanski et Arnaud Esquerre (2017), Enrichissement, on pourrait être déçu par l'absence d'une sociologie compréhensive dans une enquête qui insiste beaucoup sur l'enrichissement capitaliste par le patrimoine.

$\mathrm{Cl}$ - II y a également une autre tradition scientifique autour du patrimoine qui est constituée par les travaux de l'équipe de Daniel Fabre sur l'ethnologie des monuments historiques (Fabre \& luso 2009), sur l'histoire à soi (Fabre 2000), qui se rapproche de votre perspective compréhensive et par le bas, même si Fabre n'a jamais revendiqué une filiation avec votre travail.

HG - On est dans des publications simultanées, on n'est pas dans un rapport de dette.

Mais le travail de Fabre est le plus proche de ce que l'on a fait.

GS - Au plan intellectuel, l'enquête avait deux parrainages: un côté ethnométhodologique, constructiviste, un autre côté analyse des politiques publiques, institutionnaliste. Au-delà de la sociologie critique, l'enjeu était d'articuler les deux approches pour montrer ce qui se joue en terme de sociabilité, d'extension du champ patrimonial et de pratiques culturelles. Il s'agissait d'éviter le piège d'une forme de genèse essentialiste de la socialité, et de comprendre les conduites comme des cas de prises des politiques culturelles « résiduelles" par des amateurs, puisque l'action portait sur du petit patrimoine local. On a tenu ces deux branches problématiques, et c'est cela qui a donné sa dynamique à l'enquête.

HG - Cette enquête m'a permis de dévoiler quelque chose qui reste souvent caché, qui est ce lien au patrimoine. Je me souviens d'une discussion avec Guy où l'on parlait 
du point de vue des intellectuels sur ses appropriations patrimoniales. Je me souviens que Guy disait à propos des habitants des grandes métropoles, des Parisiens : « Oui mais eux ils n'ont pas besoin de se mettre en association pour défendre du petit patrimoine, ils vivent dedans. » Ce «ils vivent dedans », ce « à Paris, on vit au milieu des monuments historiques classés, vous ne le voyez pas ", je pense que c'est très juste et cela m'est resté. Et assez paradoxalement, on retrouve aussi cet aveuglement chaque fois que les intellectuels ne voient pas que la bibliothèque d'un chercheur fonctionne aussi comme une collection patrimoniale. Bibliothèque où il $\mathrm{y}$ a toute la philosophie, toute la sociologie, tous ces livres auxquels les intellectuels sont attachés. Et ce patrimoine, en quelque sorte, n'est pas visible. Pour le dire plus généralement, cette enquête sur les associations du patrimoine, c'était une manière de faire apparaître quelque chose qui est implicite et qui doit continuer à être implicite chez la plupart d'entre nous, peut-être un refoulé - et notamment dans la sociologie, parce que c'est lié à notre identité et notre lien au territoire et que ce sont des choses que les sociologues ne veulent pas vraiment voir, et notamment leur propre lien à leur histoire et à leur patrimoine. Se déplacer vers les associations du patrimoine, cela m'a permis de voir ce lien à travers les yeux de ces gens-là.

$\mathrm{Cl}$ - On aurait les deux lignes de votre livre: le petit patrimoine et l'approche compréhensive, à propos d'un phénomène qui n'est pas nécessairement visible pour les agents du ministère...

GS - Non seulement pas visible mais également inquiétant. Quand on analyse le champ du patrimoine, on doit inclure les stratégies au sein du champ culturel. Or, ce qui l'anime, c'est une pluralisation des expressions culturelles qui oblige ceux qui les élaborent, ceux qui en vivent et ceux qui les consomment à se positionner par rapport à cette pluralité. La pluralité est dérangeante sur un plan intellectuel, politique, économique, elle est un inconfort pour ceux qui vivent dans la tradition patrimoniale classique. 
Figure 3

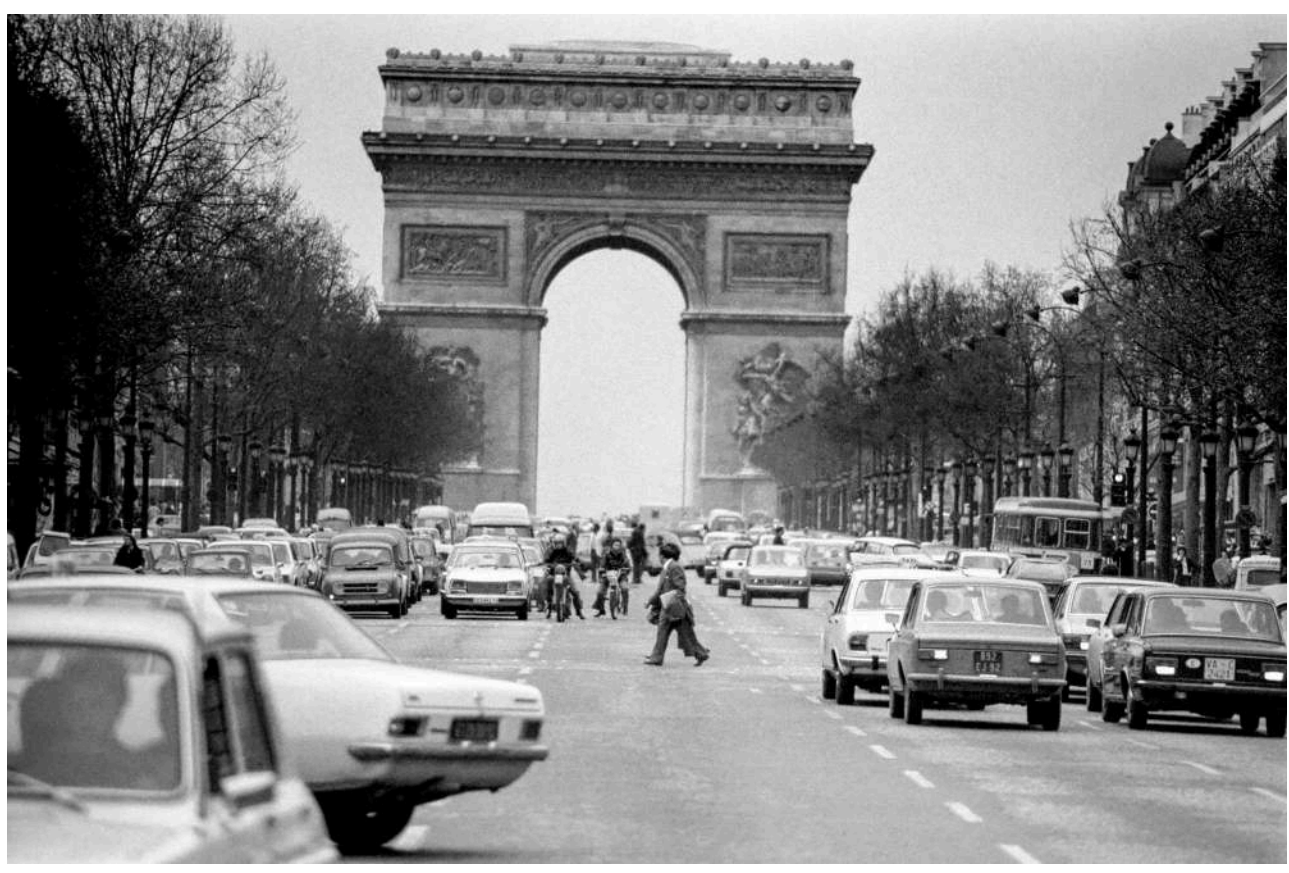

Présence et invisibilité du « grand » patrimoine dans la capitale française. L'Arc-de-Triomphe sur les Champs Élysées à Paris, 1975.

(C) Mirrorpix / Bridgeman images.

\section{Les résultats de l'enquête}

$C B$ - Après cette remise en contexte intellectuelle, institutionnelle et biographique de l'enquête, quelles seraient les conclusions du livre qui vous semblent majeures?

GS - La première conclusion, c'est qu'il n'y avait pas de relations explicites et structurées entre le monde du petit patrimoine et le monde des grandes fédérations patrimoniales qui sont les interlocuteurs habituels du ministère. Malgré cette césure, les associations du petit patrimoine ne sont pas contre le grand patrimoine, ce n'est simplement pas leur problème. Ce que signale l'investissement associatif, c'est un désir d'expression : exprimer une forme de sociabilité, d'intérêt social, de valeurs. Il y a une demande de reconnaissance minimale de ces expressions médiatisées par le lieu où l'on habite, la commune, le territoire. Il faut alors comprendre l'investissement associatif comme le vecteur de la construction sociale de la proximité, une forme de territorialisation.

HG - J'ajouterai que cette enquête a permis de comparer. Nous avons réalisé une enquête par questionnaire sur trois départements que nous avions choisis en fonction de leur richesse patrimoniale, de leur structuration administrative ou de la présence de fédérations. Ce questionnaire a permis de recueillir les objets, les vocations, les titres de ses associations. On a vu par exemple le passage de la " société » aux " amis » et enfin à l'« association du patrimoine ». Il y a donc trois temps, trois moments des associations, et nous avons bien distingué valorisation et conservation, car dans valorisation il y a valeur, il y avait aussi le terme d'animation. On était très sensibles à ces mots nouveaux et ces nouvelles formulations. Quand estce que le mot « patrimoine » est apparu ? Quand est-ce que le monument historique 
disparait ? Pour faire une typologie des associations, il fallait prendre au sérieux les évolutions et les différences, pour ne pas faire un paquet indistinct, en disant par exemple « les associations sont comme les sociétés d'histoire d'il y a un siècle ». Ce n'est pas juste, ce n'est pas la même chose, et d'ailleurs les anciennes sociétés cherchaient à évoluer. C'est l'une des choses que l'on a pu montrer.

L'autre chose, c'est d'avoir été sensible à une appropriation par le bas. On a restitué ce qu'il en était de cette appropriation par les amateurs, et nous avons découvert le souci mémoriel des acteurs associatifs, qui se manifestait par le discours d'une génération qui se disait une "génération charnière ». Aussi le mot important, c'était " rupture ». Ces gens identifiaient une rupture historique et c'est en raison de cette rupture historique qu'il fallait s'occuper du patrimoine local. On est allé voir ce que cette rupture historique voulait dire. Elle est un peu ambivalente, elle ouvre sur deux fenêtres: une fenêtre très très profonde et large, qui montre la fin d'une société industrielle et le passage à une société post-industrielle, et puis une fenêtre plus étroite qui donne sur un temps plus précis, celui des années 1960-1970 qui concerne surtout une révolution culturelle dans les valeurs. Les gens de ces générations, plutôt des retraités (mais il y avait des trentenaires également) signifiaient dans l'espace public, avec les associations du patrimoine, qu'une mémoire était à maintenir. Un des auteurs qui a le mieux dit ces choses-là, c'est Paul Ricœur (2000). Il y avait la question de la dette : on ne la critiquait pas mais on la prenait au sérieux. Ces associations nous disaient: «On a une dette vis-à-vis de nos aînés, on identifie une rupture et on ne voudrait pas que cette rupture intervienne trop brutalement. »

Le souci du patrimoine tel qu'il apparaissait chez nos enquêtés, est de maintenir ce lien au territoire, au travail et la question du quotidien, avec tous ces objets, les fers à repasser, les moulins à café, les pinces à sucre. Comme si là, précisément dans le quotidien, une rupture avait pu se produire. Mais est-ce que cette rupture s'est produite ou est-ce que cette rupture est en partie construite ou imaginaire? On a laissé le point d'interrogation, mais moi je l'ai prise au sérieux. J'ai été très sensible à cette dimension de la dette envers ceux qui nous ont précédés. 
Figure 4

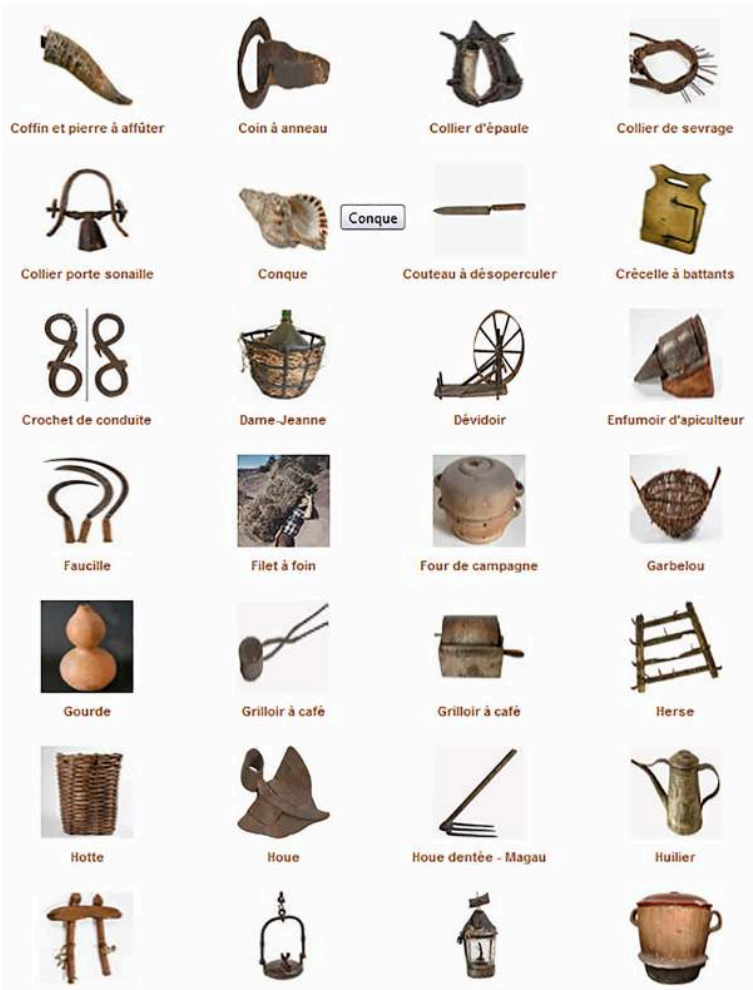

Extrait de la collection de l'Écomusée de la Roudoule en Terre Gavote, écomusée fondé en 1977, dans le département des Alpes-Maritimes qui montre l'attachement aux objets du quotidien rural, thématique centrale des collections associatives étudiées par Hervé Glévarec et Guy Saez (extrait de http://www.roudoule.com/).

GS - Un autre apport de l'enquête consiste à remettre en question la définition classique du patrimoine, comme une continuité des traditions, portée par des gens qui sont inscrits dans ces traditions culturelles. Parfois les responsables associatifs n'étaient pas de la région, ils venaient d'ailleurs; parfois aussi ils formulaient des demandes pour les espaces périurbains, là où les traditions sont à inventer, où elles ne sont pas consubstantielles au territoire. Ilya donc des entrepreneurs de patrimoine, et être entrepreneur de patrimoine ce n'est pas d'abord être inscrit dans une tradition, mais c'est vouloir inscrire l'avenir dans une dette en partie imaginaire et dans un projet de transmission. Ils se pensent comme des agents de transmission, même s'ils n'en avaient pas les propriétés sociologiques au départ.

Mais l'enquête nous a appris également quelque chose sur la vie associative: les motivations pour l'engagement dans la vie associative ne sont les mêmes que celles qui prévalaient dans la société des années 1950 et 1960, qui étaient des formes très préemptées par les grandes institutions d'encadrement social : syndicalisme, église, partis politiques. On s'engageait alors pour toute sa vie et pour une œuvre qui nous dépassait. Là, on voit des gens avec des engagements limités, labiles et révocables, plastiques, très réactifs, et des actions innovantes que des contextes plus classiques ne permettent pas. Cette capacité d'innovation est en rupture avec ce qui faisait auparavant. Mais si on regarde de manière un peu plus précise, on devrait réactiver la sociologie des dispositions : on voit de réelles asymétries entre les individus ; il y a des gens qui réussissent à fonder le musée dont ils rêvent et ils en deviennent le directeur - et puis il y a les autres. 
Ensuite, il y a la question plus compliquée qu'évoquait Hervé à l'instant : est-ce que le grand schéma de Hobsbawm sur l'invention des traditions (Hobsbawm \& Ranger 1983) est applicable à des objets qui ne sont pas la nation, et à des objets qui ne sont pas l'histoire, mais le patrimoine ? J'ai tendance à dire oui : les acteurs inventent une histoire, en partant de petites choses matérielles, ça peut être un four collectif, des outils de l'agriculture traditionnelle, une machine-outil, des ordinateurs. De même pour la notion de communauté imaginée de Benedict Anderson (1983), car ces gens construisent des musées, des collections qui donnent du sens, qui est un atout fondamental dans la construction d'un bien commun localisé.

$C B-$ Quels dispositifs des politiques publiques utilisaient ces associations à l'époque ?

GS - La question des musées est cruciale pour les associations, car pour se pérenniser elles doivent se projeter dans un espace public de type muséal. La perspective du musée leur vient assez naturellement, mais beaucoup d'entre elles refusaient le mot «musée »! Elles le remplaçaient par «maison du patrimoine », en référence aux valeurs familiales, conviviales, et mémorielles. Nous avions discuté de l'ambigüité du rapport des associations au musée, perçue comme une forme trop institutionnelle. Au contraire, elles misaient sur la pédagogie, la transmission vivante : il fallait des gens qui fassent fonctionner les objets en direct, face à un public, face à des enfants, dans le but de maintenir le fil historique et faire vivre ces objets. Ces objets ne devaient pas être "morts", comme on pense qu'ils le sont dans un musée. Il y avait cette représentation, «le musée, c'est mort », bien que les musées retrouvaient une belle vigueur depuis les années 1980. Mais la Maison du patrimoine avait comme visée d'être une maison collective, active et vivante.

$\mathrm{Cl}$ - On voit bien comment la Maison du patrimoine se situe à la marge d'un paysage muséographique très ouvert: le modèle de l'écomusée et de la nouvelle muséologie, ou bien même celui des musées de plein air qui mettent en scène les savoir-faire artisanaux devant les visiteurs.

$H G$ - Bien sûr, mais la figure de l'écomusée n'était pas la figure revendiquée. Sans doute parce qu'elle était déjà très institutionnelle, appropriée par les professionnels. Les associations ont essayé d'inventer leur propre forme d'exposition, de mise en scène et de mise en discours du patrimoine. Et la Maison du patrimoine était la formule qu'elles avaient trouvée. 


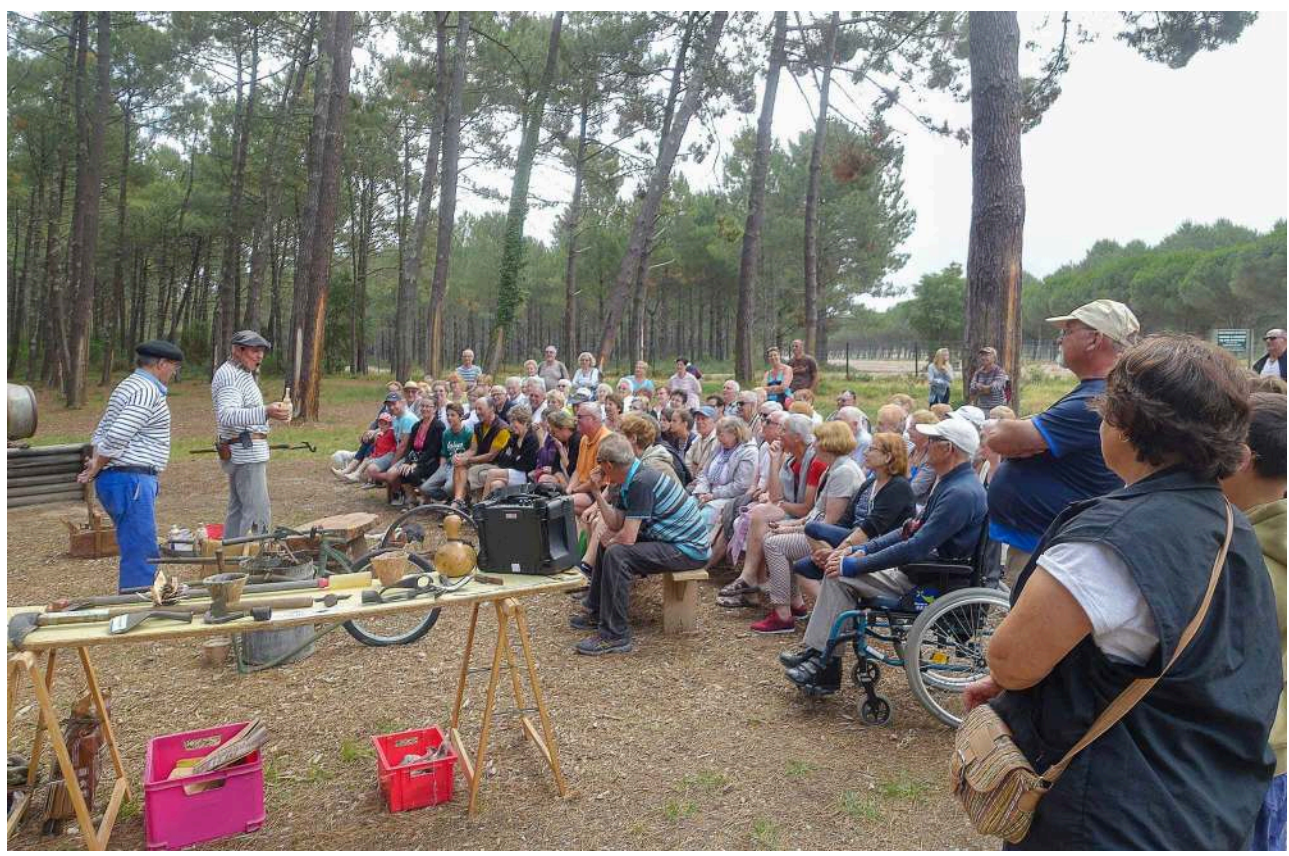

Transmission en contexte associatif patrimonial : démonstration de gemmage par l'Association socioéducative mimizanaise (Asem) qui occupe et gère la Maison du patrimoine, juin 2016.

(c) Gilbert Cabanieu (Asem, section « Histoire et traditions »).

\section{Réception de l'enquête et évolution du champ patrimonial}

Cl-Comment l'étude a-t-elle été reçue par le ministère et par les fédérations nationales du patrimoine qui en ont eu connaissance?

GS - Le ministère de la Culture est une grande maison, il faut distinguer tous les étages et les locataires de cette maison! Je pense que le DEPS a été surpris de la richesse de l'enquête et par le travail de terrain mené par Hervé Glevarec. Il a d'ailleurs fait connaître l'étude dans un numéro spécial de Développement culturel. On a eu quelques invitations, mais elles sont restées relativement peu nombreuses. La Dapa, la direction de l'Architecture et du Patrimoine, rien! Au moins sur le moment. Ensuite, j'ai été invité à plusieurs réunions à la Dapa, et l'on m'a confié une nouvelle enquête sur un sujet patrimonial, le label Ville d'art et d'histoire, preuve de la bonne réception de l'enquête. Mais on ne m'a jamais parlé du livre lui-même. Le service d'ethnologie du ministère [Mission du patrimoine ethnologique] ne m'a jamais contacté. Quant aux grandes fédérations, j'ai eu deux ou trois contacts pour me demander de présenter l'enquête, mais finalement rien d'autre. En revanche, les universitaires nous ont invité. À l'étranger, j'ai reçu des invitations de la part de collègues belges et québécois. Une équipe de l'université de Louvain m'a confié que ce qui se passait alors en Belgique était ce que nous avions étudié en France. Même commentaire chez les Québécois, car effectivement, dans tous les recoins et les petits villages du pays on est en train de voir l'apparition de groupes qui revendiquent des éléments du patrimoine, ou plutôt qui créent leur patrimoine. 
HG - Le fait est qu'en dehors du livre et de trois publications demandées curieusement par des historiens de la culture, du côté des institutions j'ai eu peu d'échos. Je suis ensuite parti sur un projet qui revenait sur la radio, et jusqu'à maintenant je n'ai pas repris cette thématique du patrimoine ducôté des associations, et l'on ne m'a pas sollicité pour la revitaliser. Mais ce peu d'écho finalement vient peut-être du fait que le département de la prospective a été dérouté par cette étude. Ils ont vu la multitude des significations et la richesse de cette appropriation du patrimoine par le bas. Nous avons montré aussi que les ambitions étaient modérées: les associations n'allaient pas tout bouleverser demain, elles n'allaient pas remplacer les professionnels, elles avaient leur territoire et souvent elles demandaient peu de choses, faciles à acquérir : avoir l'oreille du maire, pouvoir monter la maison du patrimoine, être reconnues simplement.

J'espère que l'on a contribué à faire reconnaître ce champ patrimonial associatif. Et il est vrai, comme le disait Guy au début, que ce champ est structuré en deux mondes : les grandes associations (Demeures historiques, les institutions de fouilles archéologiques, Rempart...) et puis cette foisonnante vie des associations qui se créent sans qu'on ne leur demande rien. Entre les deux, les passerelles sont très peu nombreuses. Et ce petit monde des associations que nous avons observé il y a maintenant plus de quinze ans ne s'est pas structuré en fédérations du patrimoine.

GS - En effet, il n'y a pas de fédération. Mais depuis 2004, avec la loi sur la dévolution de l'Inventaire aux régions, les choses ont changé. Nous avons étudié ce phénomène juste avant, tout juste avant que les associations n'entrent dans une autre logique, qui est celle de la logique territoriale de valorisation économique du patrimoine, aujourd'hui partout dominante. La volonté de fabriquer du patrimoine fait entrer la mémoire collective dans une logique de développement. Nous l'avions senti mais ce n'était pas encore en place aussi fortement qu'aujourd'hui. Pour autant, ce développement des territoires ruraux n'est pas une forme d'instrumentalisation du patrimoine, c'est de la valorisation. C'est différent car les valeurs de transmission et de mémoire restent fondamentales.

HG - Dans le livre, nous avons noté que la valorisation du patrimoine est vécue en effet par les associations comme un enrichissement culturel, et donc il y a les deux sens de l'enrichissement ici : économique et culturel. La dimension territoriale, culturelle, identitaire de l'appropriation du patrimoine me paraît très importante et le livre en témoigne, je l'espère.

$C B$ - J'aimerais que vous disiez quelques mots sur l'intérêt de réfléchir sur les associations dans le cadre national. Pourquoi sont-elles «bonnes à penser »?

GS - Il y a une schizophrénie française très forte, c'est l'oscillation entre Tocqueville et Hegel. On oscille toujours entre un modèle politique formé de médiations successives - famille, associations, collectifs divers - qui traduiraient et négocieraient les aspirations et les conflits de manière souple jusqu'au sommet de l'État, et la conception hégélienne où l'esprit est tout entier absorbé par l'État, où c'est l'État qui exprime la nation et qui lui imprime son devenir sans aucune médiation. Les associations sont bonnes à penser les formes du politique, notamment l'incapacité structurelle de la France à exister dans l'un ou l'autre de ces paradigmes de manière assumée. On ne peut qu'être décontenancé par la situation actuelle des associations qui est un monde très complexe et hétérogène. La croissance impressionnante du 
nombre des associations suggère une prise en charge autonome de l'espace public. Or, on a vu augmenter dans le même temps le nombre des associations et la part des dépenses publiques de l'État. Pour un tocquevillien, c'est une contradiction absolue. Pour expliquer cela, il faut admettre que l'État a besoin des associations pour faire faire ce qu'il ne peut pas faire. Un grand nombre d'associations ne vivent que parce que l'État les soutient, ce qui génère un grand débat dans le monde associatif, pour savoir si, oui ou non, il faut considérer ces associations qui vivent aux frais de l'État comme faisant partie du monde associatif.

Voilà pour un premier tabou de l'État. Le second tabou est celui de l'économie. Beaucoup d'associations s'inscrivent désormais dans le monde de l'économie, dans le monde du travail, plus ou moins dans les marges du marché et se reconnaissent dans l'économie sociale et solidaire. Notre enquête montre qu'il y a deux catégories d'associations : celles qui sont soutenues par l'État, et les petites associations, celles qui expriment autre chose et qui peuvent devenir de véritables développeurs locaux, en entrant dans la sphère de l'économie sociale et solidaire.

$H G$ - L'association est bonne à penser aussi parce qu'elle est l'outil de base dont les gens se saisissent pour structurer leur désir patrimonial. On n'a pas rencontré de groupes d'acteurs qui ne se seraient pas structurés en association pour s'occuper du patrimoine. Est-ce que c'est quelque chose qui est en train de se transformer par l'Internet et les réseaux sociaux, qui n'était pas du tout présent au moment de l'enquête? Les travaux de Manon Istasse (2017) sur le patrimoine et Facebook montrent bien qu'Internet joue un rôle. Mais la forme associative, qui est structurante en France, peut-elle être supplantée par les réseaux sociaux? Il faut poursuivre les enquêtes. Au moment de l'enquête en tout cas, l'association était bien un outil juridique de reconnaissance. Déposer les statuts d'une association autour d'un projet patrimonial, ce n'est pas rien.

Puisque j'évoque l'appropriation sur le terrain d'Internet, il semble que d'après cette chercheuse l'engagement via Facebook est un engagement très individuel, alors que ce que nous avons vu c'est du collectif. Alors, bien sûr, il y a une hiérarchisation entre les membres, entre les bénévoles, les membres actifs, et puis souvent l'association est portée par trois ou quatre personnes. Mais il y a un collectif, un nom, des locaux, un lieu de conservation. Aujourd'hui, visiblement, on a une appropriation plus individuelle, les gens prennent des photos, les mettent sur Facebook et les commentent. 


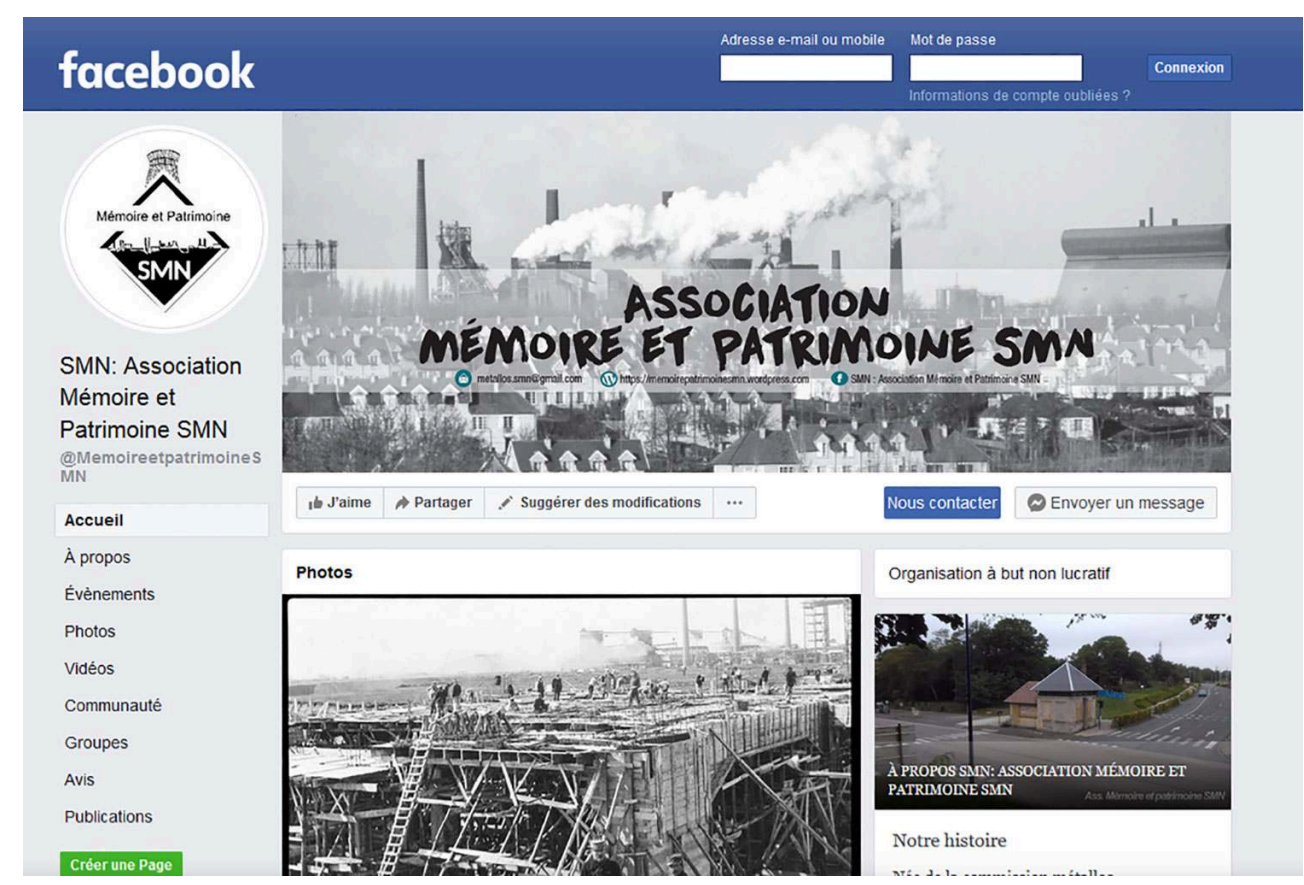

Page Facebook de l'association Mémoire et Patrimoine SMN [Société de métallurgie de Normandie], qui rend visible la présence et l'activité numérique des associations patrimoniales, 2020.

$C B$ - Vous venez d'évoquer comment le paysage patrimonial a évolué dans les dernières années, mais on pourrait revenir sur l'évolution des cadres juridiques, peut-être au niveau international, qui n'était pas présent dans votre étude.

GS - En effet, cette préoccupation n'était pas présente car les associations, avec des ressources faibles, n'avaient pas les moyens d'entretenir des relations internationales - encore que les associations bretonnes avaient des liens avec l'Irlande. Pour le reste, l'enjeu de ces associations était la construction du local, sans aucun doute, comme une réponse à la globalisation... Mais cela ne veut pas dire qu'il n'y a pas un intérêt des institutions internationales pour ce mouvement. Par exemple, la promotion du patrimoine culturel immatériel est un effet de la prise en charge localisée du patrimoine. La Convention de 2003 de l'Unesco vient entériner des mouvements de reconnaissance des cultures locales, à travers le monde entier. Le terme de reconnaissance est essentiel ici, dans le sens de Charles Taylor (1994) ou d'Axel Honneth (1995). Si on retournait sur le terrain aujourd'hui, on verrait une reconfiguration de bon nombre d'associations patrimoniales autour de la notion de patrimoine immatériel. La deuxième évolution fondamentale que je voie concerne la reconnaissance par la loi française des droits culturels au cœur de l'autre convention de l'Unesco sur la diversité culturelle (2005). Il y a donc deux instruments internationaux à disposition des entrepreneurs de patrimoine. Situation inédite, car c'est un champ nouveau et passionnant qui s'ouvre. 
Figure 7

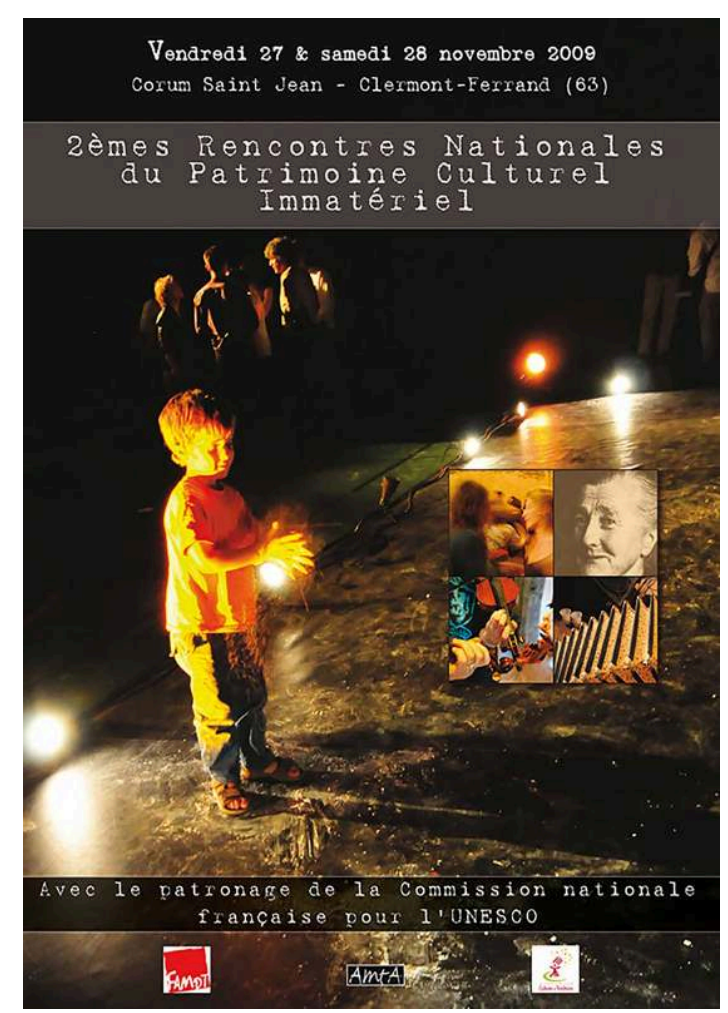

Affiche des deuxièmes Rencontres nationales du patrimoine culturel immatériel organisées par la Fédération des associations de musiques et danses traditionnelles à Clermont-Ferrand (2009), témoin de l'intérêt du secteur associatif pour la Convention de l'Unesco de 2003.

(c) Fédération des associations de musiques et danses traditionnelles.

HG - Guy soulève ici un point important, qui est celui des outils intellectuels et juridiques qui existaient à l'époque de l'enquête. Au moment de l'enquête, on ne disposait finalement que du mot de "patrimoine " qui était à l'époque relativement nouveau. Avant, il y avait les sociétés d'histoire, pas les maisons de patrimoine. Il y avait eu l'Année du patrimoine promue par le ministère de la Culture. Il y a donc toujours eu un jeu entre le discours des acteurs locaux, qui revendiquent une histoire locale et une expérience locale, et des discours internationaux, intellectuels, politiques. Des associations locales se sont créées en prenant appui sur un mot porté par les puissances publiques, voilà un peu le paradoxe de ce jeu.

GS - Parmi les choses qui ont changé, il y a la délégation du service de l'Inventaire aux régions par la loi de 2004. On peut penser a priori que cette délégation est une manière de mieux prendre en compte la diversité des patrimoines, avec deux limites cependant. D'abord, la délégation a été donnée aux régions, et non aux départements, qui pouvaient à juste titre revendiquer un régime de proximité avec les associations et les communes. La deuxième limite c'est que l'Inventaire a bien été régionalisé, mais la méthode est restée centralisée et les régions sont enfermées normativement dans la pratique nationale de l'Inventaire élaborée depuis 1964.

$\mathrm{Cl}$ - On pourrait peut-être évoquer également dans la discussion sur les reconfigurations contemporaines l'échelle transnationale : il y a maintenant des actions patrimoniales qui se 
jouent dans les communautés diasporiques ou autour d'un même objet, avec des jeux d'échelles qui modifient fortement le local.

GS - C'est une phase tout à fait nouvelle, qui est fonction des dynamiques migratoires, elle peut s'alimenter des débats sur le transnational et sur la question des tiers-lieux soulevée par Homi Bhabha (1994). Mais j'y vois aussi des hiérarchies, car il y a des jet-setters des diasporas qui ne sont pas représentatifs de ce que vit la majorité des personnes immigrées. Et il y a peut-être également un discours transculturel qui masque une partie de la réalité.

$C B$ - On voit aujourd'hui, par exemple, un champ d'action patrimonial très riche autour de migration et mémoire, qui n'apparaît pas dans votre enquête.

HG - Si l'enquête était à refaire, il faudrait élargir le monde du patrimoine à la culture en général, avec des groupes qui revendiquent des patrimoines qui n'appartiennent pas nécessairement au lieu dans lequel ils vivent... ou bien, des situations de mixité culturelle, comme en Alsace par exemple. On n'a pas d'associations culturelles liées à de tels groupes, car je crois que lors de notre recensement assez peu d'entre elles revendiquaient le terme de patrimoine. La question de l'identité, on l'a en fait attrapée par défaut, dans des associations à vocation territoriale en Bretagne ou en Alsace, on savait qu'elles étaient de ce territoire. Mais on doit bien se rendre compte que le patrimoine ne concerne plus simplement le monde associatif dans lequel nous avons enquêté. Je crois que le rapport au patrimoine s'est généralisé, s'est individualisé. Et alors que je sors à peine d'une nouvelle enquête sur les pratiques culturelles des Français adultes, je me rends compte combien la gastronomie et le rapport à l'histoire est important pour un certain nombre de personnes. Le rapport au patrimoine est donc maintenant plus individuel et de manière assez homogène. Il faudrait faire cette enquête sur le rapport des Français au patrimoine, sans forcément la médiation des associations, mais en étudiant le rapport individuel au patrimoine. 

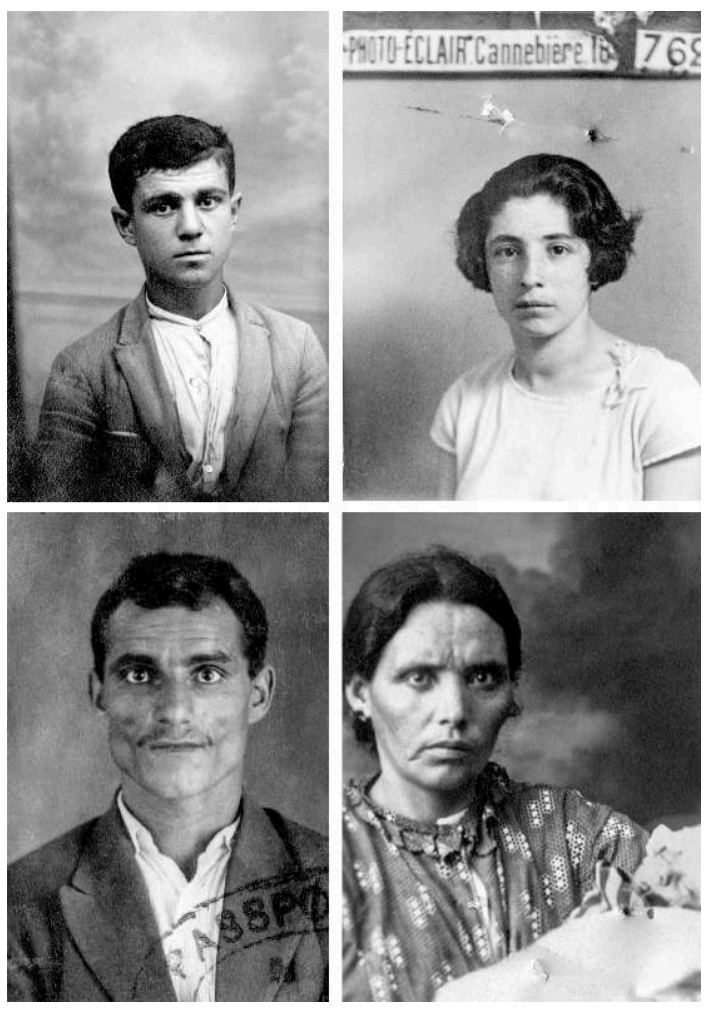

Depuis une vingtaine d'années, le thème de la migration devient un des sujets centraux des collectes et des expositions des musées de société - y compris associatifs -, entre demande de reconnaissance, fragilité des équilibres sociaux et renouvellement des institutions culturelles. " 99 portraits de l'exil - 99 photos de survivants du génocide des Arméniens » est une exposition basée sur l'agrandissement de 99 photos d'identités de réfugiés arméniens prises à leur arrivée à Marseille entre 1922 et 1926 dans le but de délivrer certificats de naissance et de baptême afin d'attester leur identité, première étape d'un long processus de reconstruction. Elles proviennent des registres de la Prélature des Arméniens du Sud de la France, et sont conservées dans le fonds documentaire de l'Association pour la recherche et l'archivage de la mémoire arménienne (Aram). De gauche à droite : Yervant Kaloustian (né le 10/05/1910), Suzanne Arakelian (née le 4/06/1909), Sahak Artin-Keusseyan (né le 17/09/1899) et Anna Bediguian (née le 9/05/1894).

Reproduction Aram (https://webaram.com/biblio/iconographie/99-portraits-de-lexil-99-photos-desurvivants-du-genocide-des-armeniens).

GS - L'an dernier, j'ai été invité à une table-ronde des Journées du patrimoine, et j'ai été frappé par le discours d'un certain nombre de responsables d'institutions patrimoniales, qui sont très inquiets d'être submergés par les touristes patrimoniaux. On n'a jamais vu autant de gens venir visiter notre patrimoine, et on ne s'est jamais autant désolé de leur comportement : « Ils passent, on ne sait pas ce qu'ils voient, ce qu'ils retiennent, ce qu'ils comprennent. En revanche on sait très bien les dégâts matériels qu'ils font. » À partir du moment où il $\mathrm{y}$ a une explosion des pratiques patrimoniales, elles sont nécessairement hétérogènes, elles délégitiment le monopole du modèle traditionnel. 
Figure 9

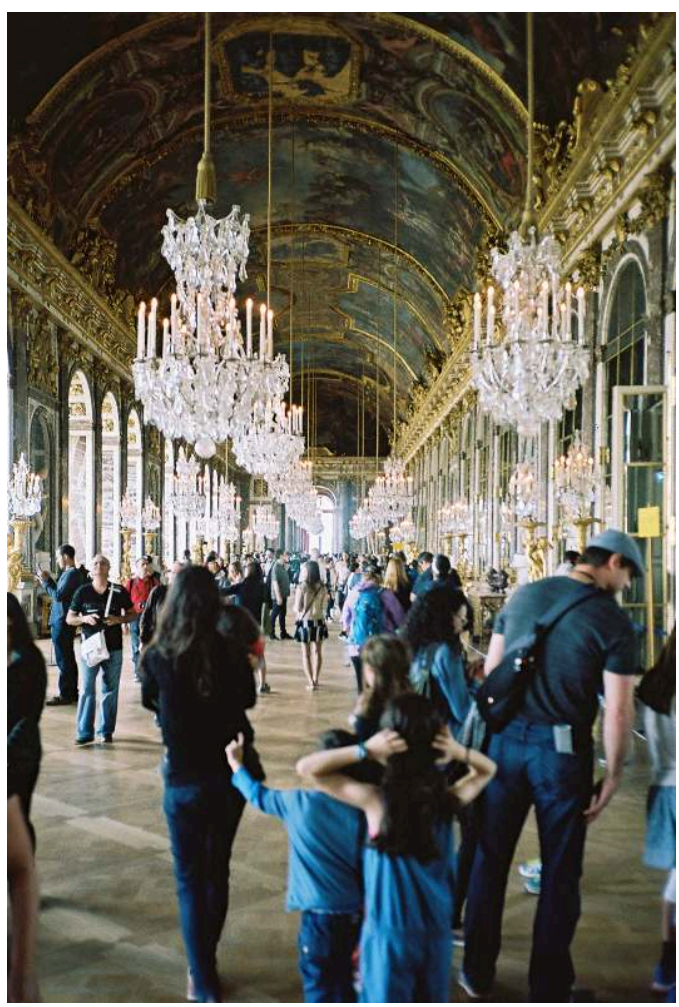

Galerie des Glaces, château de Versailles, haut-lieu d'un tourisme patrimonial dont les gestionnaires soulignent les limites et les dangers.

(c) Victorsu, dist. Flickr (sous licence CC BY-NC 2.0).

$\mathrm{Cl}$ - Vos deux dernières interventions me rappellent que les anglo-saxons ont sans doute une définition plus extensive de la notion de "heritage » que celle que nous mettons en français derrière «patrimoine». Quand nous pensons «patrimoine culturel», viennent l'administration et l'État, alors que lorsque les anglo-saxons pensent « héritage », ils voient la catégorie du patrimoine administratif, mais aussi la cuisine de la grand-mère, la culture des gens, le petit patrimoine du groupe ethnique. En vous entendant, j'ai l'impression qu'on arrive lentement à cette acception plus large du patrimoine aujourd'hui en France.

$H G$ - Ce que vous pointez c'est la bipolarisation entre le monument historique et le patrimoine, entre « notre patrimoine » et « du patrimoine ». L'État va dire c'est « du patrimoine ", et les associations vont revendiquer "leur patrimoine». Elles vont rejouer cette dichotomie, ou peut-être manifester un désir d'appropriation de ce qui est dicté par le haut, par l'administration, car c'est bien « leur patrimoine » désigné par l'Inventaire. Mais ce n'est pas celui qu'elles ont défendu par le travail bénévole, par les objets donnés, par les photographies : il est extérieur au groupe car ce n'est celui que le groupe a constitué. C'est ce que la notion d'» appropriation » a permis d'indiquer dans notre livre, l'appropriation du patrimoine en tant que pratique administrative, intellectuelle, politique et étatique. Les deux catégories jouent entre elles, bien entendu. Les associations du patrimoine sont les premières à défendre et à s'identifier à ce « patrimoine » du grand patrimoine.

GS - C'est l'effet de la pluralisation des catégories de patrimoine en France, mais faisons attention : le patrimoine culturel reste une catégorie politico-administrative. Tant qu'elle est un outil de l'État pour classer des monuments, sauvegarder et réguler des espaces, elle ne peut qu'être en tension avec ce qu'elle n'inclue pas. Cependant la 
notion est tout de même mobilisée par les gens pour eux-mêmes. Cela peut avoir beaucoup de significations: la reconnaissance d'une continuité entre le petit et le grand patrimoine ; cela peut être aussi un opportunisme comme en Grande-Bretagne où le territoire est visuellement truffé de plaques du National Heritage Fund ou de musées. Si on s'achemine vers un paysage de ce type en France, ce ne seront jamais seulement les visiteurs ou les membres de l'association qui financeront un musée ou la restauration du toit du château. L'intervention de l'État reste nécessaire : il suffit de voir le récent dispositif du Loto du patrimoine.

Figure 10

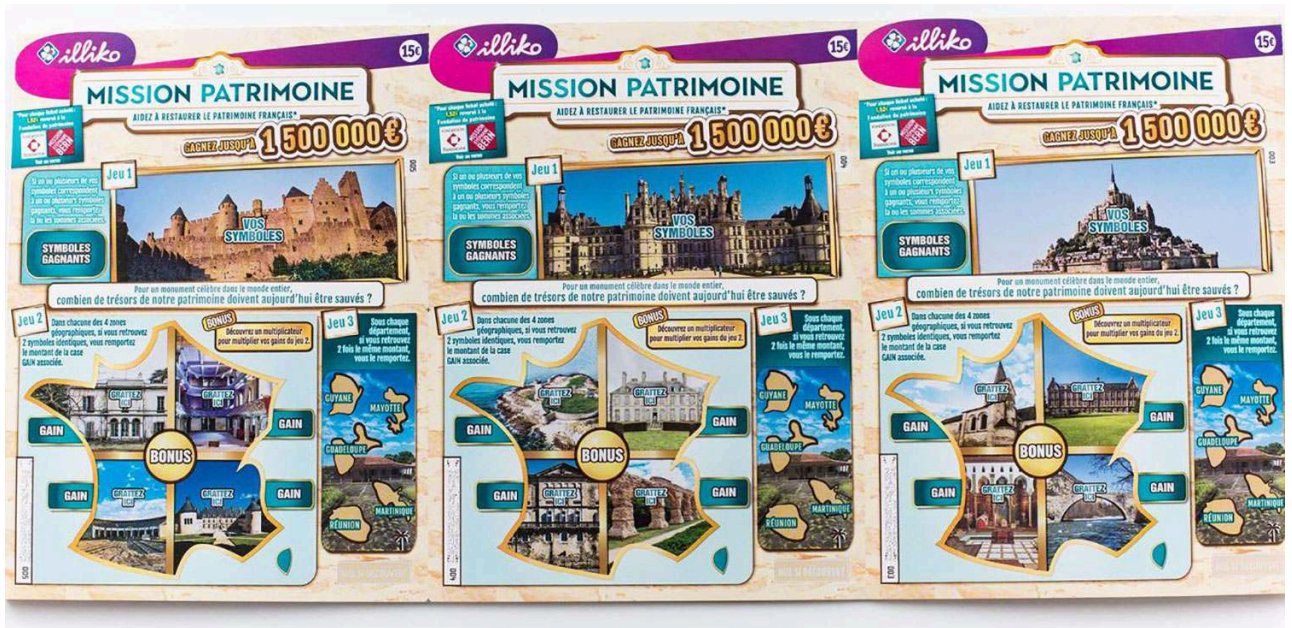

Billets du Loto du patrimoine lancé par Stéphane Bern dans le cadre de la mission confiée à l'animateur de télévision par le président de la République en 2017, afin de trouver une solution pour soutenir l'entretien et la restauration du patrimoine français.

(C) La Française des jeux.

\section{BIBLIOGRAPHIE}

ANDERSON Benedict R. O'G, 1983, Imagined communities. Reflections on the origin and spread of nationalism, Londres, Verso.

BENDIX Regina, 2002, «Capitalizing on memories past, present, and future », Theoretical Anthropology, vol. 2, n 4, p. 469-487.

BENZAÏD Redjem, 1980 [1977], L'Ethnologie de la France, besoins et projets, rapport au ministère de la Culture, Paris, La Documentation française.

BHABHA Homi K., 1994, The Location of culture, Londres, Routledge.

BOLTANSKI Luc \& ESQUERRE Arnaud, 2017, Enrichissement. Une critique de la marchandise, Paris, Gallimard, coll. « NRF essais ».

BONNIOL Jean-Luc \& CRIVELLO (dir.), 2004, Façonner le passé. Représentations et cultures de l'histoire, $\mathrm{XVI}^{\mathrm{e}}$-XXI ${ }^{\mathrm{e}}$ siècle, actes des journées d'études organisées l'UMR Telemme et l'Idemec (Maison 
méditerranéenne des sciences de l'homme, Aix-en-Provence, mai 2001), Aix-en-Provence, Publications de l'université de Provence, coll. « Le temps de l'histoire ».

CHOAY Françoise, 1992, L’Allégorie du patrimoine, Paris, Éditions du Seuil, coll. » La couleur des idées ».

DAVALLON Jean, 2006, Le Don du patrimoine. Une approche communicationnelle de la patrimonialisation, Paris, Lavoisier, coll. » Communication, médiation et construits sociaux ». DE CERTEAU Michel, 1980, L'Invention du quotidien, Paris, Union générale d'éditions.

DI MÉO Guy, 2007, « Processus de patrimonialisation et construction des territoires », in BOUFFANGE Serge \& MOISDON Pascale (dir.), Regards sur le patrimoine industriel de PoitouCharentes et d'ailleurs. Communications au colloque de Poitiers, septembre 2007, actes du colloque «Industrie et patrimoine en Poitou-Charentes : connaître pour valoriser » organisé par le service régional de l'Inventaire de Poitou-Charentes (Poitiers, 12-14 septembre 2007), La Crèche, Geste éditions, coll. «Cahiers du patrimoine », p. 87-109.

FABRE Daniel (dir), 2000, Domestiquer l'histoire. Ethnologie des monuments historiques, Paris, Éditions de la Maison des sciences de l'homme, coll. « Cahiers d'ethnologie de la France ».

FABRE Daniel \& IUSO Anna (dir.), 2009, Les monuments sont habités, Paris, Éditions de la Maison des sciences de l'homme, coll. « Cahiers d'ethnologie de la France ».

GLEVAREC Hervé \& SAEZ Guy, 2002, Le Patrimoine saisi par les associations, Paris, La Documentation française, coll. » Questions de culture ».

GRAVARI-BARBAS Maria \& GUICHARD-ANGUIS Sandra, 2003, Regards croisés sur le patrimoine à l'aube du XXI e siècle, actes du colloque international éponyme (Paris, 7-9 octobre 1999), Paris, Presses de l'université de Paris-Sorbonne, coll. « Asie \& géographie ».

HARTOG François, 2003, Régimes d'historicité. Présentisme et expériences du temps, Paris, Éditions du Seuil, coll. » La librairie du XxI ${ }^{\mathrm{e}}$ siècle ».

HOBSBAWM Eric J. \& RANGER Terence (dir.), 1983, The Invention of tradition, Cambridge / New York, Cambridge University Press.

HONNETH Axel, 1995, The Struggle for recognition. The moral grammar of social conflicts, Cambridge (Massachussetts), Polity Press.

ISTASSE Manon, 2017, « Facebook et les amateurs de patrimoine. Participation, engagement et démocratie », Réseaux, nํ 206, vol. 6, « Décoder les programmes », p. 193-218. Disponible en ligne, www.cairn.info/revue-reseaux-2017-6-page-193.htm [lien valide en juin 2020].

JEUDY Henri-Pierre, 2001, La Machinerie patrimoniale, Paris, Sens \& Tonka, coll. « 10/vingt », série « Essai ».

LENIAUD Jean-Michel, 2002, Les Archipels du passé. Le patrimoine et son histoire, Paris, Fayard.

MACDONALD Sharon, 2002, « On "old things". The fetishization of past everyday life ", in RAPPORT Nigel (dir.), British subjects. An anthropology of Britain, Oxford / New York, Berg, p. 89-106.

MICOUD André, 2005, « La patrimonialisation : redire ce qui nous relie ? », in BARRÈRE Christian, BARTHÉLÉMY Denis, NIEDDU Martino \& VIVIEN Franck-Dominique, Réinventer le patrimoine. De la culture à l'économie, une nouvelle pensée du patrimoine ?, Paris, L'Harmattan, coll. « Gestion de la culture et du secteur non lucratif », p. 81-97. 
POMIAN Krzysztof, 2003, Des saintes reliques à l'art moderne. Venise-Chicago, XIII ${ }^{e}-\mathrm{XX}^{e}$ siècle, Paris, Gallimard, coll. « Bibliothèque des histoires ».

POULOT Dominique, 2006, Une histoire du patrimoine en Occident, XVIII ${ }^{e}-X X I^{e}$ siècle. Du monument aux valeurs, Paris, Presses universitaires de France, coll. « Le noeud gordien ».

RAUTENBERG Michel, 2003, La Rupture patrimoniale, Grenoble, À la croisée, coll. « Ambiances, ambiance ».

RICCEUR Paul, 2003, La Mémoire, l'histoire, l'oubli, Paris, Éditions du Seuil, coll. « L'ordre philosophique ".

SAGNES Sylvie, 2000, « Un monument peut en cacher un autre. Rieux-Minervois et sa rotonde », in FABRE Daniel (dir.), Domestiquer l'histoire. Ethnologie des monuments historiques, Paris, Éditions de la Maison des sciences de l'homme, coll. « Cahiers d'ethnologie de la France », p. 55-70.

SMITH Laurajane, SHACKEL Paul A. \& CAMPBELL Gary (dir.), 2011, Heritage, labour and the working classes, Londres, Routledge, coll. « Key issues in cultural heritage ».

TAYLOR Charles, 1994, Multiculturalism. Examining the politics of recognition, Princeton, Princeton University Press.

TORNATORE Jean-Louis, 2004, « La difficile politisation du patrimoine ethnologique », Terrain, no 42, « Homme / femme », p. 149-160.

\section{NOTES}

1. Les variations nationales de ces mouvements pourraient bien entendu faire l'objet de développements nuancés, mais cette exposition dépasserait le cadre de cette présentation.

2. Dominique Jamet, historienne, a travaillé au ministère de la Culture jusqu'en 2011. Elle a notamment publié (avec Geneviève Gentil), Politiques culturelles. Études et documents, 1976-1983, Paris, La Documentation française, 1984; (avec Jean Fosseyeux \& Christian Pattyn), Les Établissements publics sous tutelle du ministère de la Culture. Histoire administrative, Paris, ministère de la Culture / La Documentation française, 2004.

\section{AUTEURS}

\section{CLAIRE BULLEN}

Postdoctorante, University of Tübingen / CNRS (UMR Idemec, Aix-en-Provence)

clairebullen@gmail.com

\section{CYRIL ISNART}

Chargé de recherche au CNRS, Aix Marseille Université / CNRS (UMR Idemec, Aix-en-Provence) isnartc@gmail.com 


\section{HERVÉ GLEVAREC}

Directeur de recherche au CNRS, Institut de recherche interdisciplinaire en sciences sociales (Irisso, université Paris Dauphine)

herve.glevarec@dauphine.psl.eu

\section{GUY SAEZ}

Directeur de recherche émérite au CNRS, université Grenoble Alpes / Sciences Po Grenoble guy.saez@umrpacte.fr 